\title{
AOR
}

Selected Papers of \#AolR2020:

The $21^{\text {st }}$ Annual Conference of the

Association of Internet Researchers

Virtual Event / 27-31 October 2020

\section{MEASURED EDUCATION: SENSING, CONFIGURING, AND INTERVENING WITH ADVANCED MEDIA}

Kevin Witzenberger

University of New South Wales

Kalervo Gulson

University of Sydney

Sam Sellar

Manchester Metropolitan University

Ben Williamson

University of Edinburgh

Elizabeth de Freitas

Manchester Metropolitan University

This panel sits between science, technology and society (STS), digital governance, network governance, critical data and algorithm studies. The engagement of educational research with this larger body of work stem from the entanglement of it with new forms of knowledge production and shifting sites of expertise and authority to morethan-human actors. From the storage of educational data and the application of machine learning to student management systems, to small tech companies that rely on the APIs of Microsoft Azure and Amazon Web Services, to advanced data sciences and the involvement of Google's Tensor Flow. The values, data practices, actors and the political economy of the Internet are deeply interwoven with the lives of students.

The first paper shows how ideas from data analytics move into education through research and businesses. The paper examines the spaces of educational trade shows and learning analytics conferences as 'windows' into discursive regimes to understand how the idea of measurable and re-configurable bodies is being stabilized and normalized within education. The paper presents juxtaposing thick descriptions from these events as multi-sited event ethnography in local spaces that feature transnational elements. 
The second paper looks at facial recognition in education. The paper problematizes the role of doubt in machine learning and its implications on different applications within education. The authors explore responses to doubt and argue that a 'human in the loop' to make the outputs of machine learning explainable within education contexts creates its own set of issues about machine-human relationships, including the ways in which computer vision in classrooms is part of hybrid control systems that focus on augmenting teacher control to modulate student behaviours.

The third paper looks at the generation of bioinformatic policy objects. The author argues that the field of education research is undergoing significant transformation towards data-intensive and life-sensitive sciences. The author examines a series of interrelated studies in fields of behavioural genetics and genoeconomics that generate new knowledge through bioinformatic analyses of complex associations between genes and educational outcomes. The author shows how these research projects produce bioinformatic policy objects that shape implications and proposals for government education policy but are also mobilised to support policy proposals that rekindle longstanding concerns over the role of biology in eugenics and scientific racism.

The fourth paper focuses on smart architecture in learning and living spaces that create a situation of ubiquitous sensation, in which environments are continuously sensed, regulated, and controlled through complex sensory ecosystems and data infrastructures. Outside of the predominant imaginaries of smart architecture as mechanisms for technological optimisation and biopolitical governance that serve the neoliberal agenda, the author asks what ought to be by exploring possible modes of intervention into the technical milieu. The paper discusses examples of smart schools where the ethical and political implications of sensor data are considered, exploring the ways that digital infrastructure is meant to cultivate capacity for affective bonds between students and the built environment.

What connects these papers is more than the spaces, ideas and practices that surround education. All of these papers look ideas of datafied knowledge about human life whether in behavioural, physiological, emotional, or genetic form. The panel aims to show what critical education research can learn from other disciplines, but also how it can contribute to understand phenomena in media. The panel will show both, the ways in which developments in education are influenced by technological developments in media, business, finance, and government, but also, how it can contribute to the wider discourse around science, technology and society. 


\title{
RECONFIGURING STUDENTS: STABILIZING THE OPTIMIZABLE SUBJECT
}

\author{
Kevin Witzenberger \\ University of New South Wales
}

Predictive practices in K-12 education have become ordinary and education has become a site of data mining (Williamson 2017), computational intervention and optimisation (Gulson \& Webb, 2018). New Internet of Things (IoT) technology in education combine biosensors, digital learning platforms and school surveillance systems. These new networks render education into a ubiquitous and pervasive computing environment that encompasses the lives of students. The generation of automated data collection was the first step within the 'cascading logic of automation' (Andrejevic, 2020). It has since expanded into automated knowledge discovery (Perrotta \& Selwyn, 2019) and automated responses with the goal to configure and reconfigure the minds and bodies of students. This paper asks how students and machines are figured together within this system of automation by looking at EdTech trade shows and research conferences as 'windows' into ongoing discourses of the future of education.

With the move from the OECD away from cognitive learning models towards social and emotional skills, particular interest is being paid to affective computing. In its simplest form affective computing is a form of computation that can recognize the emotions of its user. It 'relates to, arises from, or deliberately influences emotions' (Picard, 1997, p. 3). This turn within education towards machines that can read and respond to emotions and re-configure their behaviour to optimise students' emotional wellbeing, physical safety and performance constitute a 'sociotechnical imaginary', a vision of a desirable future, which is 'collectively held, institutionally stabilized, and publicly performed' (Jasanof, 2015, p. 4 emphasis added).

This paper sees this imaginary as a 'discursive regime' (Foucault, 1977) that normalizes data mining practice aimed at students and the automated feedbacks that become possible through affective computing. The paper describes what the discursive regime of automation in education entails, how and by whom it is being performed and stabilized. The paper presents fieldwork from two key spaces to better understand this discursive regime: the 'marketplace of ideas', and the marketplace itself. The former is the space in which the idea of biotechnologies are sold to society in academic settings (Stiegler, 2014) and the latter is the space in which technologies are co-opted from the marketplace of ideas and sold by vendors to educational institutions.

This approach takes inspiration from Kitchin, who describes that the discursive drive towards big data solutions is often being pushed by vendors to sell big data solutions to governments (Kitchin, 2014, p. 116). The author of this paper examines an international academic conference on learning analytics as the marketplace of ideas and an educational technology (EdTech) trade show as the spaces in which these ideas are sold by vendors to educational institutions. Both of these spaces can be considered as 'windows' into interlocking discourses that 'work to produce certain atmospheres' 'in 
which the oxygen of certain kinds of thought seems natural and desirable (Amin \& Thrift, 2013, as cited in Kitchin 2014). The set of interlocking discourses around educational trade shows and where the ideas are brought to life can be seen as 'policy events', as '[e]ducation technology agenda-setting and governance is increasingly played out through the buying and selling of goods and services' (Player-Koro, Bergviken Rensfeldt, \& Selwyn, 2018, p. 685).

The paper offers a thick description (Geertz, 1975) through notes and visual material from passive observations (see also Spanò \& Taglietti, 2019), marketing and research material. The juxtaposition of ethnographic fieldwork materials from different events should be understood as multi-sited event ethnography, which illustrates the practices that stabilize the discursive regime of automation in education in local spaces that feature transnational elements.

While both of these sites seem to be disconnected at first, as many scholars in the field of learning analytics criticise the speed in which ideas are brought to the EdTech market, and the promises that are being made by vendors, they are connected through a fundamental belief that life and learning can be measured, processed, configured and reconfigured. This becomes visible by looking at the purpose and use of technologies such as facial mood recognition, eye tracking, interaction-, process data and learning platforms within both, the commercial EdTech sector and the academic learning analytics space. Upon close examination, these spaces reveal that cybernetics and its 'essential concepts have been absorbed deeply into the fabric of contemporary thought' (Hayles, 2010, p. 155). Both are connected through the attempt to redefine what the bodies and minds of students are through the means of experimentation, and the assumption that 'the phenomenon as isolated and reworked under laboratory conditions is essentially the same as the one found in 'nature' (Stengers, 1997, p. 6).

\section{References}

Amin, A., \& Thrift, N. J. (2013). Arts of the political : new openings for the left. Durham and London: Durham and London : Duke University Press.

Andrejevic, M. (2020). Automated media. New York: Routledge.

Foucault, M. (1977). Discipline and punish : the birth of the prison (1st American ed.). New York: Pantheon Books.

Geertz, C. (1975). The interpretation of cultures : selected essays. London: Hutchinson.

Gulson, K. N., \& Webb, P. T. (2018). 'Life' and education policy: intervention, augmentation and computation. Discourse: Studies in the Cultural Politics of Education, 39(2), 276-291. doi:10.1080/01596306.2017.1396729

Hayles, K. N. (2010). Cybernetics. In W. J. T. Mitchell \& M. B. N. Hansen (Eds.), Critical Terms For Media Studies. Chicago: Tne University of Chicago Press. 
Jasanof, S. (2015). Future imperfect: science, technology, and the imagination of modernity. In S. Jasanof \& S.-H. Kim (Eds.), Dreamscapes of Modernity: sociotechnical imaginaries and the fabrication of power (pp. 1 - 33). Chicago, IL: University of Chicago Press.

Kitchin, R. (2014). The data revolution : big data, open data, data infrastructures \& their consequences. London: Sage Publications Ltd.

Perrotta, C., \& Selwyn, N. (2019). Deep learning goes to school: toward a relational understanding of Al in education. Learning, Media and Technology, 1-19. doi:10.1080/17439884.2020.1686017

Picard, R. (1997). Affective Computing. Cambridge: MIT Press.

Player-Koro, C., Bergviken Rensfeldt, A., \& Selwyn, N. (2018). Selling tech to teachers: education trade shows as policy events. Journal of Education Policy, 33(5), 682703. doi:10.1080/02680939.2017.1380232

Spanò, E., \& Taglietti, D. (2019). Disentangling the National Plan for Digital School: the Micro-dis-positivity of the Futura Event. International Journal of Sociology of Education, 11. doi:10.14658/pupj-ijse-2019-1-10

Stengers, I. (1997). Power and Invention. Minneapolis: University of Minnesota Press.

Stiegler, B. (2014). States of shock: stupidity and knowledge in the 21st century. Malden, MA: Polity Press. 


\title{
HUMANS IN THE LOOP: FACIAL RECOGNITION, DOUBT, AND EDUCATION GOVERNANCE
}

\author{
Kalervo Gulson \\ University of Sydney
}

Sam Sellar

Manchester Metropolitan University

The introduction of facial recognition into classrooms is part of new ways in which Artificial Intelligence (Al), specifically machine learning and computer visions, is being introduced into different areas of education governance. The aim of this paper is to use the example of facial recognition to discuss the following: 1) the way that the use of machine learning involves doubt in the calculations, and that doubt has different implications depending on the application; 2) that one response to doubt is to make automation explainable (that is, what does a machine learning algorithm do?) by putting the 'human in the loop'; and 3) to look at how humans in the loop of facial recognition applications in education contexts create new problematizations about machine-human relationships, including notions of augmentation.

The introduction of $\mathrm{Al}$ into education governance is part of a broader realm of datafication, ostensibly aimed at improving and accelerating the production of educational knowledge, to make all problems anticipatable, measurable, calculable and solvable. Research in this area has focused on: empirical studies of new data infrastructures for educational governance and new policy actors (Gulson \& Sellar, 2019; Hartong, 2018); the intensification of computational approaches to public policy work over the past decade (Gilbert, Ahrweiler, Barbrook-Johnson, Narasimhan, \& Wilkinson, 2018); automated decision making (Zarsky, 2016) and the 'bias' towards automation (Andrejevic, 2019).

The paper is interested in the ways in which doubt is central to the mathematical underpinnings of machine learning and its application in governance areas. This follows Louise Amoore's (2019) conceptualisation that there are technical and political roles for doubt in machine learning. First to the technical. Most simply, machine learning is probabilistic. This is important in our discussion of education governance for the use of statistics has been to analyse the frequency of past events as a way to inform policy decisions. Machine learning is premised on probability, and its application in education has been around predictive governance - the likelihood of how likely a future event will occur and how to make decisions on that basis. What Amoore reinforces, is that probability is a form of doubt, that embraces errors and inaccuracies in order for a machine learning algorithm to train and develop. The second role of doubt is political. When machine learning provides an output, when a decision is provided, whether that be about providing entry to a student to university, or in a film recommendation, Amoore suggests that this decision 'is placed beyond doubt' $(2019, \mathrm{p} .5)$. The key point is that machine learning decisions are inherently uncertain but presented as authoritative. 
We are interested in the ways in which putting humans in the loop attempts to address the combination of the technical and political doubt. The first way is a design decision in 'Human In The Loop' machine learning, where people are involved in an iterative process of training, tuning, and testing a particular algorithm. The second is technical where another algorithm will show what is happening in a 'black box'. The third is to have a human decide whether and in what context an algorithm is to be used. And the fourth is that the humans in the loop are also those who are not only using but are the object of the technology. What all of these instances point to is, as West, Whittaker and Crawford (2019) ask, 'which humans are in the loop'?

In the paper, we discuss this question through the example of facial recognition. Doubt and humans in the loop are combined in facial recognition in the criticisms that the data used in training facial recognition are biased, the technology is not accurate, and people of colour are being unfairly locked out of 1-1 facial recognition systems (Stark, 2019). The solution to doubt is often posed as more accurate training data. However, the problem is that inclusion is not always a solution, in that more accurate system means populations already under heavy surveillance become more accurately monitored (Benjamin, 2019).

We conclude the paper by examining the ways in which these issues arise in education governance. The application of facial recognition within education is expanding with multiple use values put forward such classroom use in China (e.g., for pedagogical reasons), as part of school responses to violence in the US (e.g., for safety reasons), and attendance taking in Australia and Sweden (e.g., for time saving reasons) (Andrejevic \& Selwyn, 2019). Our aim is to think through issues with facial recognition through the notion of a policy problematization, an approach primarily concerned with developing opportunities - creative possibilities - rather than understanding a situation as problematic that requires a single solution, often conceptualized as a 'silver bullet' in education policy (Webb \& Gulson, 2015). This includes the ways in which computer vision in classrooms is a part of hybrid control systems that focus on augmenting teacher control to modulate student behaviours. Our key focus in this part of the paper is on the ways in which problematising the human in the loop in machine learning may help us to understand the changing machine-human relations of education governance.

\section{References}

Amoore, L. (2019). Doubt and the algorithm: On the partial accounts of machine learning. Theory, Culture \& Society, O(0). doi:10.1177/0263276419851846

Andrejevic, M. (2019). Automated media. London and New York: Routledge.

Andrejevic, M., \& Selwyn, N. (2019). Facial recognition technology in schools: critical questions and concerns. Learning, Media and Technology, 1-14. doi:10.1080/17439884.2020.1686014

Benjamin, E. (2019). Race after technology: Abolitionist tools for the new Jim Code. Cambridge: Polity. 
Gilbert, N., Ahrweiler, P., Barbrook-Johnson, P., Narasimhan, K., \& Wilkinson, H. (2018). Computational modelling of public policy: Reflections on practice. Journal of Artificial Societies and Social Simulation, 21(1), 1-14.

Gulson, K. N., \& Sellar, S. (2019). Emerging data infrastructures and the new topologies of education policy. Environment and Planning: Society and Space, 37(2), 350366.

Hartong, S. (2018). Towards a topological re-assemblage of education policy? Observing the implementation of performance data infrastructures and 'centers of calculation' in Germany. Globalisation, Societies and Education, 16(1), 134-150. doi:10.1080/14767724.2017.1390665

Stark, L. (2019). Facial recognition is the plutonium of AI. XRDS: Crossroads, The ACM Magazine for Students, 25(3), 50-55.

West, S. M., Whittaker, M., \& Crawford, K. (2019). Discriminating systems: Gender, race and power in $A l$. Retrieved from https://ainowinstitute.org/discriminatingsystems.html

Webb, P. T., \& Gulson, K. N. (2015). Policy, geophilosphy, education. Rotterdam: Sense Publishers.

Zarsky, T. (2016). The Trouble with Algorithmic Decisions: An Analytic Road Map to Examine Efficiency and Fairness in Automated and Opaque Decision Making. Science, Technology, \& Human Values, 41(1), 118-132. doi:10.1177/0162243915605575 


\title{
BIOINFORMATIC POLICY OBJECTS: BODIES AND MACHINES IN DATA-INTENSIVE AND LIFE-SENSITIVE SCIENCES
}

\author{
Ben Williamson \\ University of Edinburgh
}

The expansion of data science over the last decade has been accompanied by significant claims about the changing status of knowledge and expertise. 'Datafied knowledge production' (Thylstrup, Flyverbom \& Helles, 2019) has been made possible by technical advances in computational statistics, data analytics, and machine learning algorithms, as well as novel expert data practices in computer science, informatics, data science and software engineering (Mackenzie 2017). These technologies and practices have become extremely valuable in a wide range of knowledge-producing fields, as the data analytics industry has expanded from technical development to the media, business, finance, entertainment, government, the public sector, and research (Beer, 2019). The field of education research is currently undergoing significant transformation into a field of datafied knowledge production, as new actors invested with the authority of data science have begun undertaking novel 'big data' studies into the embodied substrates of human learning. These developments stand to reposition education research as a datafied science, and to make human bodies and life itself into objects of education policy. This work-in-progress paper provides an examination of educational data sciences as an exemplar of the ways in which datafied knowledge production is increasingly bringing human life into the calculations of public policy and governance.

According to the OECD, educational research in the 2020s should emulate the application of advanced digital technologies in the life sciences of biology, cognitive science and neuroscience in order to have relevance for policy and practice (Kuhl et al, 2018). The life sciences have become increasingly 'data-intensive' with the emergence of advanced computational power, data analytics and machine learning (Leonelli 2016; Stevens, 2017). The development of datafied life sciences is also introducing 'lifesensitive' practices of biological, physiological and neural sensing into other diverse domains, with 'techno-somatic real-time sensing' technologies that can capture the 'rhythms' and 'metronomic vitality' of human bodies escaping their disciplinary enclosures to inhabit new spaces of knowledge production and governance (Davies 2019). Exemplifying the expansion of datafied life sciences as a mode of technosomatic knowledge production, data scientific techniques are now being applied to new research tasks and 'automated knowledge discovery' in education (Perrotta and Selwyn 2019). Researchers of education and learning are seeking novel, data-intensive and life-sensitive science methods for creating policy-relevant knowledge about 'life itself', and exploring possibilities for its intervention and augmentation (Gulson \& Webb, 2018).

While the roles of knowledge-based technologies in educational policy and governance are well-documented (Fenwick et al, 2014), pressing need remains for studies unpacking the specific apparatuses and practices of data-intensive science that are involved in producing policy-relevant knowledge. This paper takes as its empirical focus an ongoing controversy over data-intensive biological methods for educational knowledge production by examining a series of recent interrelated studies in fields of 
behavioural genetics (Plomin, 2018) and genoeconomics (Benjamin et al, 2012). Based on analysis of genetic samples collected from up to a million research subjects, these studies have generated new knowledge through bioinformatic analyses of complex associations between genes and educational outcomes (attainment, test performance, achievement and non-cognitive skills), as well as longer-term socio-economic and life outcomes, and traits such as intelligence (Lee et al 2018; Plomin \& von Stumm 2018; Harden 2020). Such bioinformatics studies are paradigmatic of the emergence of dataintensive, life-sensitive science as a means of producing new policy knowledge in education. They are producing new kinds of bioinformatic policy objects-novel datafied renderings of human lives and bodies created in such a way to shape implications and proposals for government education policy. However, the results are also highly controversial and the subject of significant debate, with conservative commentators mobilizing the findings to support policy proposals that have rekindled longstanding concerns over the role of biology in eugenics and scientific racism.

Through examining the scientific work involved in educational bioinformatics studies, the paper addresses the question of what specific roles advanced computational technologies perform in the production of datafied knowledge about human life. Drawing on science and technology studies (STS) research on the ways 'bioinformation' and 'biodata' are used, treated and manipulated to create knowledge (Parry \& Greenhough, 2018), it focuses attention on relations between objects, technologies and forms of expertise in this process: human samples, bioinformatics infrastructure, laboratory hardware and software, disciplinary knowledge practices, ontologies and epistemologies, research coalitions, and funding mechanisms. The relational apparatus of bioinformatics, like other fields of datafied knowledge production, not only carries authority to 'discover' or 'reveal things' but also to 'bring into being the very objects they are meant to describe and represent' (Ruppert, 2018, 19). As biological science has transformed into bioinformatics, 'computers have altered out understanding of "life", as 'biological objects' have been 'virtualized' as codes, and 'databases and algorithms determine what sorts of objects exist' for analysis and knowledge generation (Stevens, $2013,5)$. The bioinformatic policy objects produced through datafied educational sciences are calculable, networked bodies generated through the infrastructure of biobanks, bioinformatics technologies, bio-scientific methods, and the scientific epistemologies of behavioural genetics and genoeconomics. The paper illuminates the complex human and nonhuman work involved in producing policy-relevant scientific knowledge, and the implications of data-intensive and life-sensitive sciences for how living human subjects are known and governed.

\section{References}

Beer, D. (2019). The Data Gaze. London: Sage.

Benjamin, D.J., Cesarini, D., Chabris, C.F. et al. (2012). The Promises and Pitfalls of Genoeconomics. Annual Review of Economics 4, 627-662.

Davies, W. (2019). The political economy of pulse: Techno-somatic rhythm and realtime data. Ephemera 19(3), 513-536. 
Fenwick, T. Mangez, E. \& Ozga, J. (eds). (2014). Governing Knowledge: Comparison, knowledge-based technologies and expertise in the regulation of education. London: Routledge.

Gulson, K. \& Webb, P.T. (2018). 'Life' and education policy: intervention, augmentation and computation. Discourse: Studies in the cultural politics of education 39(2), 276-291.

Harden, P. (2020). Investigating the Genetic Architecture of Non-Cognitive Skills Using GWAS-by-Subtraction. Medium: https://medium.com/@kph3k/investigating-thegenetic-architecture-of-non-cognitive-skills-using-gwas-by-subtraction$\underline{\text { b8743773ce44 }}$

Kuhl, P.K., Lim, S.-S., Guerriero, S. \& van Damme, D. (2019). Developing Minds in the Digital Age: Towards a science of learning for $21^{\text {st }}$ century education. Paris: OECD.

Lee, J.J., Wedow, R., Okbay, A., et al. (2018). Gene discovery and polygenic prediction from a genome-wide association study of educational attainment in 1.1 million individuals. Nature Genetics 50, 1112-1121.

Leonelli, S. (2016). Data-Centric Biology: A philosophical study. London: University of Chicago Press.

Mackenzie, A. (2017). Machine Learners: Archaeology of a data practice. London: MIT Press.

Parry, B. \& Greenhough, B. (2018). Bioinformation. Cambridge: Polity.

Perrotta, C. \& Selwyn, S. (2019). Deep learning goes to school: toward a relational understanding of Al in education. Learning, Media and Technology: https://doi.org/10.1080/17439884.2020.1686017

Plomin, R. \& von Stumm, S. (2018). The new genetics of intelligence. Nature Reviews Genetics. doi:10.1038/nrg.2017.104

Plomin, R. (2018). Blueprint: How DNA makes us who we are. London: Allan Lane.

Ruppert, E. (2018). Sociotechnical Imaginaries of Different Data Futures: An experiment in citizen data. Rotterdam: Erasmus University.

Stevens, H. (2013). Life Out of Sequence: A data-driven history of bioinformatics. London: University of Chicago Press.

Stevens, H. (2017). A Feeling for the algorithm: Working knowledge and big data in biology. Osiris 32, 151-174.

Thylstrup, N.B., Flyverbom, M. \& Helles, R. (2019). Datfied knowledge production: Introduction to the special theme. Big Data \& Society, July-December: https://doi.org/10.1177/2053951719875985 


\section{AFFECTIVE ATHMOSPHERES AND SMART ARCHITECTURE}

Elizabeth de Freitas

Manchester Metropolitan University

As Luciana Parisi (2017) argues, the environmental distribution of sensation between living bodies, buildings, and digital media is more than a computational network that simply processes 'information'. These systems are capable of collecting and processing continuous streams of biometric and environmental data from buildings and their inhabitants, including data collected from fingerprint scanners, facial recognition software, surveillance cameras, movement sensors, light sensors, and wearable biosensing technologies. Parisi (2009) conceptualises these architectural networks as "technoecologies of sensation" which achieve a collective nexus of sensibility and dynamic response that moves seamlessly "between organic and inorganic matter" ( $p$. 192). Dynamically mediated streams of sensory data become diffuse, elemental, and atmospheric, opening onto a massively distributed environmental sensibility rather than remaining tied to individual bodies as processers of information and perception (de Freitas, 2018).

It's evident that digital life is lived in relation to sense, sensation and affect in radically new atmospheric ways (Anderson \& Ash, 2015; Burke, 2014). We are no longer dealing with nodes and connections in a network, but rather with the atmospheric conditioning of a climate of thought, sensation, and technicity (McCormack, 2018; Simondon, 2017). Considered as complex sensory ecosystems that operate through the ubiquitous biomediation of life processes, smart buildings have the potential to support the cultivation of an atmospheric "data-sense" that plugs directly into the "microtemporal qualities of experience" (Hansen, 2015, p. 132).

In this paper I focus on smart architecture and how it is producing a situation of "ubiquitous sensation", in which learning and living environments are continuously sensed, regulated, and controlled through complex sensory ecosystems and data infrastructures (de Freitas \& Rousell, 2018). Precisely because current applications of the internet of things serve neoliberal political agendas in the context of architecture, we need to start thinking concretely about how to use sensor technologies differently for designing, modifying, and inventing learning environments that reclaim affective and somatic relationality (Akawara \& Gins, 2002; Coenen, Coorevitz, \& Lievens, 2015).

I argue that there is a need to develop artful and playful disruptions of these data infrastructures, as a way of resisting the crude materialism of smart architectural designs in which machinic matter is meant to flow naturally into the "becomingenvironment of computation" (Parisi, 2017, p. 79). At the same time, I am wary that an uncritical embrace of 'relationality' is problematic if it functions to simply naturalize 
computation and support techno-governance in design and architecture (Parisi, 2017). My interest in artful interventions then is not an attempt to dispel critiques of the computational logic now shaping the built environment, but to explore possible modes of intervention into the technical milieu.

In attempting to think beyond predominant imaginaries of smart architecture as mechanisms for technological optimisation and biopolitical governance, I will consider the work of Mexican-Canadian artist Rafael Lozano-Hemmer on "relational architecture" (Lozano-Hemmer, 2011, 2019). Relational architecture entails experimental interventions that "expose the body and society's receptivity to instability, fluctuation and re-imagining" (p. 87). Lozano-Hemmer (2005) describes how relational architecture involves a distinct shift from an imaginary of "interactivity" in which the building is meant to facilitate interaction amongst humans towards a new paradigm of posthuman technicity and flow. And yet Colebrook (2019) warns us that such work can seem very naïve, or worse, entail a kind of "implicit moralism" which often seems intent on rescuing a humanity through spreading its relations, finding itself again and again in its monstrous inventions and digital stretch (p.175). Celebrations of relationality can be rather self-serving ways of depoliticizing frictional encounters, failing to accept limits and incommensurables. Refusing to let being 'be' without relation can be a way of colonizing the world with digital infrastructure, part of the ongoing colonialism of telecommunication' revolutions.

Such concerns are raised here especially in light of the new biopower at stake in sensor technology and smart architecture. As Gabrys (2016) explains, 'natural' ecologies of the planet itself are now linked through sensor technologies; Hörl (2017) asserts in related fashion that we must rethink 'general ecology' as a term that is utterly technical. This paper will discuss some examples of smart schools where the ethical and political implications of sensor data are considered, exploring the ways that digital infrastructure is meant to cultivate capacity for affective bonds between students and the built environment.

\section{References}

Anderson, B. and Ash, J. (2015). Atmospheric methods. In Vannini P (ed.) NonRepresentational Methodologies: Re-Envisioning Research. London: Routledge, pp. 34-51.

Arakawa, S. and Gins, M. (2002). The Architectural Body. Tuscaloosa: University of Alabama Press.

Burke, C. (2014) Looking back to imagine the future: Connecting with the radical past in technologies of school design. Technology Pedagogy and Education 23(1): 3955. 
BBC News. (Oct 6, 2016). Virtual cat is newest 'pupil' at Cambridge school. Available at: https://www.bbc.co.uk/news/uk-england-cambridgeshire-37561326 (accessed 18 September 2018).

Colebrook, C. (2019). A cut in relationality: Art at the end of the world. Angelaki: Journal of the Theoretical Humanities 24(3): 175-195.

Coenen, T., Coorevits, L. and Lievens, B. (2015). The wearable Living Lab: How wearables could support Living Lab projects. In: Open living lab days 2015, Istanbul, Turkey.

de Freitas, E. (2018) The biosocial subject: Sensor technologies and worldly sensibility. Discourse: Studies in the Cultural Politics of Education 39(2): 292-308.

de Freitas, E. and Rousell, D. (2018) Atmospheric intensities: Sensing the places and times of learning through bioaffective technologies. In: Affects, interfaces, events conference, Aarhus, Denmark, 26-30 August 2018.

Gabrys, J. (2016). Program Earth: Environmental Sensing Technology and the Making of a Computational Planet. Minneapolis: University of Minnesota Press.

Hansen, M.B. (2015). Feed-Forward: On the Future of 21st Century Media. Chicago, IL: University of Chicago Press.

Hörl, E. (2017). Introduction to general ecology: The ecologisation of thinking. In: Hörl E and Burton JE (eds) General Ecology: The New Ecological Paradigm. London: Bloomsbury, pp. 1-75.

Lozano-Hemmer, R. (2011). "Articulated Interesect." Triennale Que'becoise 2011, Place des Festivals, Muse'e d"Art Contemporain de Montre' al, Montre' al, Que'bec, Canada.

Lozano-Hemmer, R. (2019). Atmospheric Memory. Manchester International Festival.

McCormack, D. (2018). Atmospheric Things: On the Allure of Elemental Envelopment. Durham: Duke University Press.

Parisi, L. (2009). Technoecologies of sensation. In: Herzogenrath B (ed.) Deleuze Guattari \& Ecology. Hampshire: Palgrave Macmillan, pp. 182-199.

Parisi, L. (2017). Computational logic and ecological rationality. In: Hörl E (ed.) General Ecology: The New Ecological Paradigm. London: Bloomsbury, pp. 75-100.

Simondon, G. (1958/2017). On the Mode of Existence of Technical Objects (trans C Malaspina and J Rogove). Minneapolis, MN: Univocal. 